\title{
Interview with Martin Gnass and Martin Kolbe on "Challenges and Hot Topics in the Intermodal Logistics Industry"
}

\author{
André Ludwig • Milena Stróżyna
}

Published online: 15 July 2020

(c) Springer Fachmedien Wiesbaden GmbH, ein Teil von Springer Nature 2020

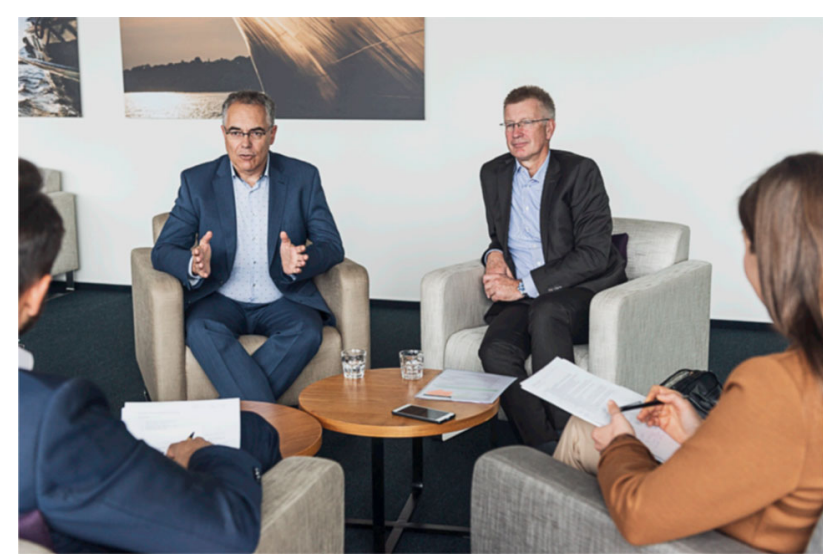

Martin Kolbe, Chief Information Officer (left)

Kuehne + Nagel AG

Martin Kolbe is a graduated computer scientist. He has held various positions in IT management, including IT Field Manager at Deutsche Post World Net, responsible for DHL Europe and DHL Germany. Since 2003, he is working for Kuehne + Nagel International AG as the CIO. Martin Gnass, Managing Director IT (right)

Hapag Lloyd AG

Martin Gnass is a graduated industrial engineer from Hamburg University. From 1990 until 2003 he held IT Consulting and Management positions at Andersen

\footnotetext{
A. Ludwig ( $\square)$

Kühne Logistics University, Großer Grasbrook 17,

20457 Hamburg, Germany

e-mail: Andre.Ludwig@the-klu.org
}

\section{Stróżyna}

Poznań University of Economics and Business, al.

Niepodległości 10, 61-875 Poznań, Poland

e-mail: milena.strozyna@ue.poznan.pl
Consulting and IBM Global Services. Since 2003, he has been working at Hapag Lloyd AG. He is currently the Managing IT Director responsible for IT strategy, technological innovation and business value generation.

BISE: What are the current challenges along the intermodal transportation chain that you observe in your daily business?

Kolbe: There's a lot of complexity in our business, many partners are digitally disconnected despite running businesses similar in nature. Each carrier provides services a bit differently, creating different types of data, which makes end-to-end processing complex to work with. In the Courier-Express-Parcel business, the carrier has the advantage that it owns the assets during transportation and can dictate which protocols are followed. We lack this luxury in the intermodal transport industry, there is no standardization, each company runs its own protocols. Competition keeps businesses from openly sharing their data with partners. Data is the most important asset of the future, especially reliable, transportable, real-time data. Also, we are currently still dealing with a lot of paper. This should be automated by using OCR scanning or AI technology.

Gnass: In our liner courier company, we not only transport on ocean decks, but we also offer a significant amount of intermodal and inland business. The management of these services makes us operate under a complex digital ecosystem. Also, data standardization is limited which makes data exchange more complex. There's a lack of data quality, consistency, and accuracy, so the first step for is consolidating the data to create reliable supply chain information services for our customers. Another area that we find has significant potential for improvements are technical interfaces. We've been using EDI for more than 
20 years and it's not real-time. We still end up with time lags and data consistency issues.

BISE: You both mentioned data and standardization. Do you feel there is enough data available and what standardization efforts do you see in the industry?

Gnass: Standardization has been on the agenda for many years. We don't have standards like the aviation sector, i.e. driven by IATA (International Air Transport Association). We launched an initiative in 2019 establishing a non-profit association called DCSA - Digital Container Shipping Association. We, as a shipping liner, are striving for increased standardization in order to obtain easier collaboration.

Kolbe: We have more than enough data. There's a desire to become faster and to disregard standardization. The fast track involves plugging in smart sensors, which is just not affordable when a ship has 20,000 containers. Then there's the sensors' data, someone has to figure out what data is really valuable. A smart container with AI capabilities that can sort through all the data, build models and combine sources to build an information platform, that would make a difference. What we have now is information about the transportation, so we aim to make the intermodal transportation more transparent. The right data is definitely the key to overcoming the situation, we just don't know if standardization is faster or if it's better to fast track it with IoT devices on the containers ourselves.

BISE: Data in intermodal transportation is highly decentralized. Which potential do you see for blockchain technology in your industry?

Gnass: There's a hype around Blockchain in our industry. I believe that if we want to be successful, though, we have to do it together, we have to work with our business partners, customers, and even competitors to establish governance structures and platforms to provide a framework and foundation to successfully adapt this technology. It's also an opportunity for relevant players in our logistics businesses to actively shape new digital ecosystems. Potentials I can see are the secure and efficient handling of documents across the logistic chain. It could also be used for handling bill of ladings and the secure management of containers.

Kolbe: In my view, blockchain is limited in large scale use because we need the right data, at the right time, in a way that pays for itself. Right now, this is neither cheap nor easily available. Blockchain is valuable in its reliability, documentation, and traceability of what and who makes changes. The downside is, this doesn't help with smaller partners, they usually don't have the capabilities to join the blockchain. There's also a lack of trust in the industry and no desire to exchange data. Then there's the technical partner providing the blockchain. They have all the data, and so you need to ask what are they doing with it? We recently launched our own blockchain portal that tracks container measurements. It increases visibility in terms of the weight of the container and helps ensure that all changes are documented and auditable.

BISE: What is your vision of how to better estimate the risk and reliability in your industry?

Gnass: Reliability and commitment is extremely important. We're collaborating with ports, like the Port of Hamburg, to reinforce our commitment in providing quality and reliable services. As for risks, there's been the development of cyber warfare in our industry. We've invested a significant amount of funds in developing a strong information security management system. We've also added additional prevention, detection, monitoring and recovery procedures to build a robust and resilient system.

Kolbe: From a different perspective, we've developed a platform for customers that makes carriers more transparent. The platform allows customers to select different routes by rates, $\mathrm{CO} 2$ emissions, most reliable time and our ratings on the reliability of carriers based on prior performance. We're also using Big Data for preventative measures, such as historical weather data to make predictions and give real-time visibility and ETAs (expected time of arrival) on shipments so the customer can be proactive about what to do next. Our platform also provides visibility, so customers are able to take measures to minimize product loss. As for risk, we've built up our own team that actively handles difficult situations, making quick decisions as these arise.

BISE: With regard to cyber security, is there a logistics platform that shares knowledge regarding cyber security and detected threats?

Gnass: When it comes to cyber security, we use IT experts who have a lot of experience and knowledge in this area. It's hardly possible to build on all competences, so we also have a team in place with the knowledge and capabilities to oversee governance and the management of our IT service providers. In a sense, using third party cyber security companies is a sort of knowledge sharing center.

Kolbe: It's similar for us, the technology is the same. Logistic companies also need to comply with standards because the market is directly impacted. The standstill of containers can lead to shortages. Another security issue that hasn't been much in focus yet in the market are smart sensors. This is a great new technology, but security measures are fragmented and not standardized. There's the possibility that if one sensor gets a virus, that virus could spread. A shipment can have twenty thousand sensors. There's currently no way to handle such a situation. There's a lot of new data, new systems, and processes creating more risk and we must find a way to deal with all this.

BISE: Let's discuss how the industry is currently changing. What is the likelihood that new actors, startups, 
and e-platforms will take away market shares from incumbent players?

Gnass: Recently, startups have begun to provide smart solutions to customers. They are pushing the market to further innovation and digitization. The downside for these new businesses is that their ambitions and progressive ideas aren't always feasible. Their drive has pushed larger incumbents to really focus on digitalizing and finding smart approaches for themselves. Have we seen any disruption in the market? Not yet. One change in the market is that size matters and we have experienced huge consolidations in our industry in recent years. We are at a time where we have to be able to manage business on a certain scale while also cutting down the unit costs.

Kolbe: We're providing end-to-end services, and I see new players making progress, though they have trouble with more complex, intermodal logistics. We have the people, the industry knowledge, and the underlying IT systems in place. I agree that there hasn't been a huge disruption. It's different when it comes to the large companies like Amazon or Alibaba, they have more funds, capabilities and IT knowledge. We've also taken a lot of countermeasures and increased our capabilities on the digital front. We've invested in new digital platforms, but not all customers have responded well to it. They think 'why should I start entering data? Nobody's paying me for that'. Also, technologies that use AI have the advantage of providing better services.

BISE: So what I'm hearing is that startups aren't too disruptive. What about other drivers such as customers wanting to purchase locally or technological advances, like 3D printing? Do you see any risks here?

Gnass: In recent years, we've changed how we do business and we can say that we're still seeing a modest global growth in cargo volumes. However, the growth can be affected by challenges such as trade wars and trade restrictions. The market has changed, though, as we are experiencing larger volume growth in emerging markets. Trade patterns are changing. To what extent globalization will change to becoming local remains to be seen. Also, different customer expectations are emerging, such as policy quality concerns and sustainability. Tougher regulations are being considered for emissions this year and this will be a huge challenge for us to cope with.

Kolbe: We've noticed local markets growing. There are opportunities as long as the services are complex enough, or else we have to compete with local market players. Whenever a job becomes more complex or needs certain service capabilities, that's where we make our money. As for 3D printing, I don't see that this will empty the harbor.

BISE: As a final question, how do you see the role of academia, researchers, and research institutions in helping you address the challenges you face in your companies?

Gnass: For us, we're very use-case driven, so applied research is a strong area in which we look for assistance. Another domain is technological innovations; as technology plays a major role, there are always opportunities to explore.

Kolbe: If I had a wish list, data scientists focusing on logistics would definitely be on it. We need scientists looking into the complexities of logistics so we can better understand the dynamics, especially when IT sensors start kicking in. There's also an increased need for AI and predicting algorithms with deep learning elements. We recently looked at new startups in Asia which are applying these types of technologies and they have helped us to better plan for the complexities we face in trade and yield management.

BISE: Mr. Gnass, Mr. Kolbe, thank you very much for your time and for sharing your opinion with the BISE community. 